\title{
Noise exposure and auditory thresholds of military musicians: a follow up study
}

Reinhard Müller ${ }^{{ }^{*}}$ and Joachim Schneider ${ }^{2}$

\begin{abstract}
Background: Military musicians are working in a noisy environment with high sound exposure levels above the international standards. Aim of the current study is to find out, whether they develop the expected hearing impairments. Adherence to the regulations for prevention in musicians is more difficult than in other occupational fields.

Methods: In an interval of 13.3 years, 36 out of 58 male military musicians of a German army music corps were subjected twice to an audiometric audit. There were no exclusion criteria apart from acute ENT infections (three musicians). These results were compared with one another and evaluated by means of statistical methods for relationships with several factors.

Results: At frequencies below $3 \mathrm{kHz}$, the follow-up audiograms were up to $5 \mathrm{~dB}$ better than the preliminary examination. From $4 \mathrm{kHz}$ up to $8 \mathrm{kHz}$ the preliminary investigations showed less hearing impairment. Averaging all frequencies the improvement of hearing ability was around $1 \mathrm{~dB}$. Above $1 \mathrm{kHz}$ the average hearing of the right ear was up to $7 \mathrm{~dB}$ better than that of the left ear. Age-induced hearing loss was 3 to $8 \mathrm{~dB}$ lower than predicted by ISO standards over the entire frequency range. The side of the ear (right/left) and the frequency $(3,4$, and $6 \mathrm{kHz})$ were significant $(p<0.05)$ in hearing loss, whereas the influence of the instrument and the acoustic traumata were not.

Conclusion: Despite the high noise levels, the average hearing ability of the 36 military musicians during the investigation period only slightly deteriorated in the noise-sensitive frequencies (3, 5 and $6 \mathrm{kHz}$ ). Music may be less harmful than industrial noise, or the long-term auditory training of the musicians leads to a delayed presbycusis.
\end{abstract}

Keywords: Military musicians, Audiometry, Hearing, Hearing loss, Noise exposure

\section{Background}

At the time of the old Israelites, trumpets are said to have been able to bring whole city walls to collapse, according to the relevant account in the Old Testament of the Bible, in Joshua 6. Even today, brass orchestras are able to produce a significant sound pressure, which may be felt in a larger radius. While lovers of military music appreciate these brass instruments and the sound, the usually excessive volume encounters refusal, especially with gentler natures. But not only military orchestras can produce high sound pressure levels but even ballet orchestras are suspected of hearing hazard [1].

\footnotetext{
* Correspondence: reinmu@gmx.net

1Justus-Liebig-Universität Giessen, Aulweg 123, 35392 Giessen, Germany

Full list of author information is available at the end of the article
}

The musicians as parts of the sound source themselves are more exposed to these sounds than the audience in some distance and should therefore take a greater risk to develop noise induced hearing loss. In order to determine these sonic loads, appropriate measurements were made in some studies. These relate predominantly to classical orchestras. Since the number of military musicians on the whole seems rather small, their hearing is rarely subject of published investigations. A search in PubMed with the search query: "military musicians" AND "hearing"> provides only three matches. One of these articles [2] complains about the below-average poor health surveillance of military musicians without commenting on their hearing status, so that only two articles remain. Both were published in 2013. While a 
Brazilian study [3] reports an approximately 15-fold increased risk of hearing loss of military musicians compared to an unimpaired population, Patil et al. [4] reports no increased risk of hearing damage in British Army musicians compared to military administrative personnel. In 1981 Axelsson and Lindgren [5] already described in a larger study the hearing ability of orchestral musicians, that military music poses no increased risk of developing hearing damage compared to orchestral music. For most musicians with noticeable hearing damage ( $>80 \%$ ), a connection could be established with the music practice. Sound measurements in orchestras performed during rehearsals and public performances predominantly indicate level margins and average values which exceed the upper exposure action value of $85 \mathrm{~dB}(\mathrm{~A})$ on daily shift [6]. McBride et al. [7] report up to $160 \%$ of the allowed daily dose on an average day with rehearsals and concert. According to ISO 1999 [8], therefore, the effects of sound exposure on the ear should be found. Mostly, however, lower levels of hearing loss are found in musicians than the ISO 1999 [8] predicts [4, 9-15]. Female musicians heard equally well as their male counterparts of the same age group [11, 16]. Several authors reported a better hearing of the right ear compared to the left ear [5, 14, 16, 17]. Especially with violinists, the volume of their own instrument is a dominant factor [18]. The left ear near the instrument is averagely exposed to $4.6 \mathrm{~dB}$ more than the right ear, which is averted from the instrument. In a literature study on the sonic load and hearing of musicians Sataloff [19] comes to the conclusion that musicians can produce dangerous sound levels, but further investigations would be necessary with regard to the effect on the hearing. A German study [20] to the hearing status of orchestral musicians found more than $50 \%$ musicians with hearing loss $\geq 15 \mathrm{~dB}$ and equivalent sound exposure levels $\mathrm{L}_{\mathrm{EX}}>90 \mathrm{~dB}(\mathrm{~A})$.
Overall, there is a rather heterogeneous picture regarding the hearing of musicians in the literature, which presents partly contradictory results and is not always comparable in terms of methodology. An important step towards standardization could be the application of a new parametric method by Bo et al. (2016) for the noise risk assessment of professional orchestral musicians [21]. The present longitudinal study examines military musicians who have been audited twice at intervals of more than 13 years. As the first examination [22] was carried out, sound measurements were also taken during rehearsals and concerts. A typical rehearsal with the musicians in a rehearsal room with corresponding sound measurements is shown in Fig. 1.

All microphone positions, with values up to $93 \mathrm{~dB}$ (A), show equivalent sound exposure well above the upper exposure action values [6].

The comparison of two audiograms to the same persons should enable to make reliable statements about the development of hearing or the development of a hearing damage in these persons under sound exposure far above the upper exposure action values [6].

\section{Methods \\ Participants}

Out of a total of 58 male military musicians of the army music corps in Bremerhaven 39 musicians could be tested a second time after about 13 years. Only complete data sets were evaluated. Three musicians who suffered from a cold were excluded. A total of 36 musicians could be evaluated in the present longitudinal study. Existing hearing damage was not an exclusion criterion, as only the development of hearing was of interest, whilst comparing the two hearing tests.

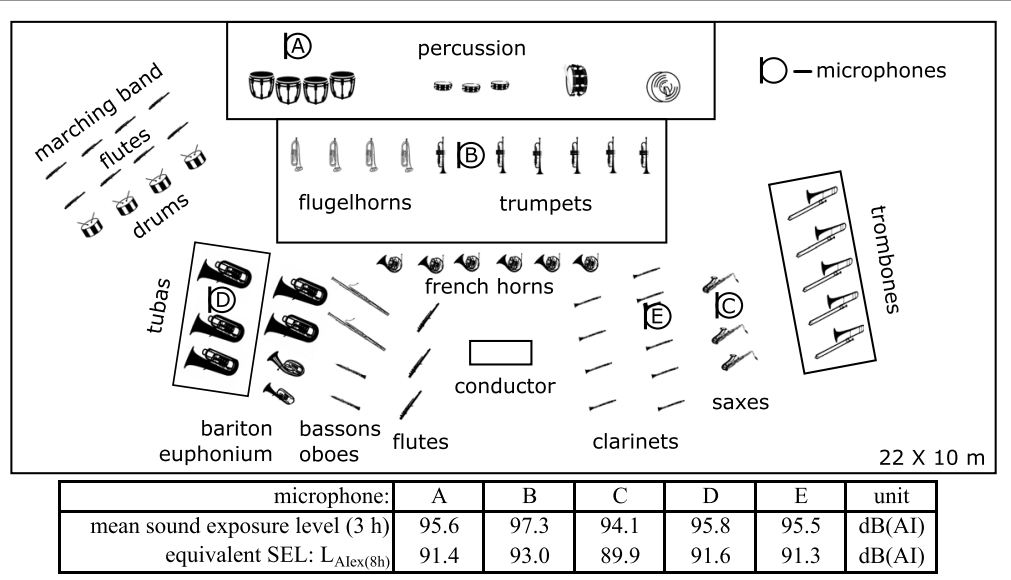

Fig. 1 Military musicians at a three hours rehearsal with sound measurements at 5 microphone positions a-e. Mean sound exposure levels within $3 \mathrm{~h}$ and recalculated Levels to one working shift: $\mathrm{L}_{\text {Alex(8h) }}$ in $\mathrm{dB}(\mathrm{Al})$. (Illustration modified from F. Pfander, 1985) [22] 


\section{Instrumentation}

For the audiometry 4 audiometers of the company Hortmann type CA540 and an audiometer of the company Maico type MA53 in connection with circum-aural transducers type HDA200 of the company Sennheiser were used. These transducers were calibrated according to ISO 389-8 [23] and ISO 389-5 [24]. Hearing tests were performed with pulsed sine tones. The data was displayed and stored with the software Avantgarde 2.0 of the company Nuess via the serial interface RS 232 in PCs.

The first audiometry tests were performed with audiometers from Siemens type T31 and Beomat 2005 SR with supra-aural transducers from Beyer type DT 48 with sinusoidal tones. The tranducers were calibrated according to ISO 389-1 [25]. The audiometers were not yet connected to computers, but the hearing thresholds were entered on cardboard forms of the manufacturers. For the evaluation, the threshold values were transferred individually into a database.

\section{Acoustic measurements}

The acoustic measurements during the rehearsal were carried out by the technicians of Pfander [22]. The measurements were performed with three $1 / 2$ inch free-field microphones type 4165 (at A, B and C) and two $1 / 2$ inch free-field microphones type 4133 (at D and E). All with preamps type 2619 and amplifier type 2606 of Brüel \& Kjær (Danmark). The measure points A, B and C were recorded with a level statistics device type 4426 of Brüel \& Kjær, and the points D and E with a PCM-recorder combination PCM-F1/SL-F1E from the company Sony (Japan).

\section{Software und statistics}

The data processing was carried out with the Office programs Access and Excel Microsoft Office 2010, whereby even simple T-tests were used. The age-related hearing loss from ISO 7029 (2nd and 3rd editions) [24, 25] was also calculated in Excel and included for comparison. A repetitive multivariate ANOVA was performed using SPSS 15 with 3 inner-subjects factors (repeat) audiogram, frequency and ear and 2 between-subjects factors instrument and acoustic trauma. The statistical evaluation addressed the frequencies 3,4 and $6 \mathrm{kHz}$, in which all datasets were complete. Only at $10 \mathrm{kHz}$ three musicians had missing data values. One of these musicians had no value on both ears and two only on the left ear.

\section{Results}

\section{Hearing thresholds}

At intervals of about 13.3 years (mean age of the groups 31.4 and 44.7 years) military musicians of the German Federal Armed Forces were checked twice by means of audiometry and questioning.
In Fig. 2 the average hearing ability of the musicians for both the right and left ear as well as at the time of the first measurement (Audio1) and 2nd measurement (Audio2) is shown separately. With the exception of the frequency at $125 \mathrm{~Hz}$ in the left ear, a hearing improvement was observed in both ears over all frequencies below $2 \mathrm{kHz}$ over time, ranging from 1 to $4 \mathrm{~dB}$. At $2 \mathrm{kHz}$, on average there was no change. At $3 \mathrm{kHz}$, the hearing thresholds behave differently in both ears. Over time, the right ear has improved by about $1 \mathrm{~dB}$ while the left ear has deteriorated by about $1 \mathrm{~dB}$. Between 4 and $8 \mathrm{kHz}$ the later audiometry shows a 2 to $5 \mathrm{~dB}$ worse hearing than the first examination. At $10 \mathrm{kHz}$, a slight improvement in hearing thresholds can be observed. Overall, the hearing of the right ear is slightly better than the left, which is shown in Fig. 3.

Figure 3 shows the averaged differences in auditory thresholds (Audio 2 minus Audio 1) for left and right ear seperately. These differences were compared to the current standard on hearing ISO 7029:2000 [26] and also to the new draft ISO 7029:2014 [27] for the age group between 31.4 and 44.7 years in the same diagram. It can be seen from this, that there are clear deviations between the expected and the measured hearing losses. Based on the new ISO standard (dashed black line in Fig. 3), the expected hearing loss is lower than for the still valid ISO from the year 2000 (solid black line in Fig. 3). The hearing loss differences in military musicians between both measurements across all frequencies is similar to the difference according to ISO aging. Almost across all frequencies, the military musicians show less age impaired hearing compared to the predicted aging

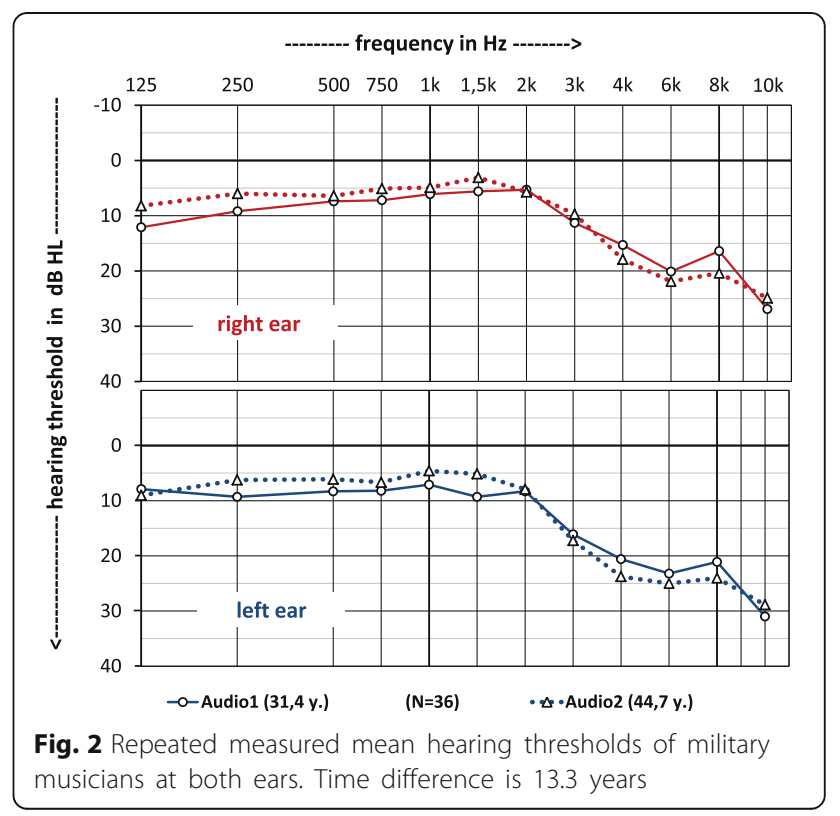




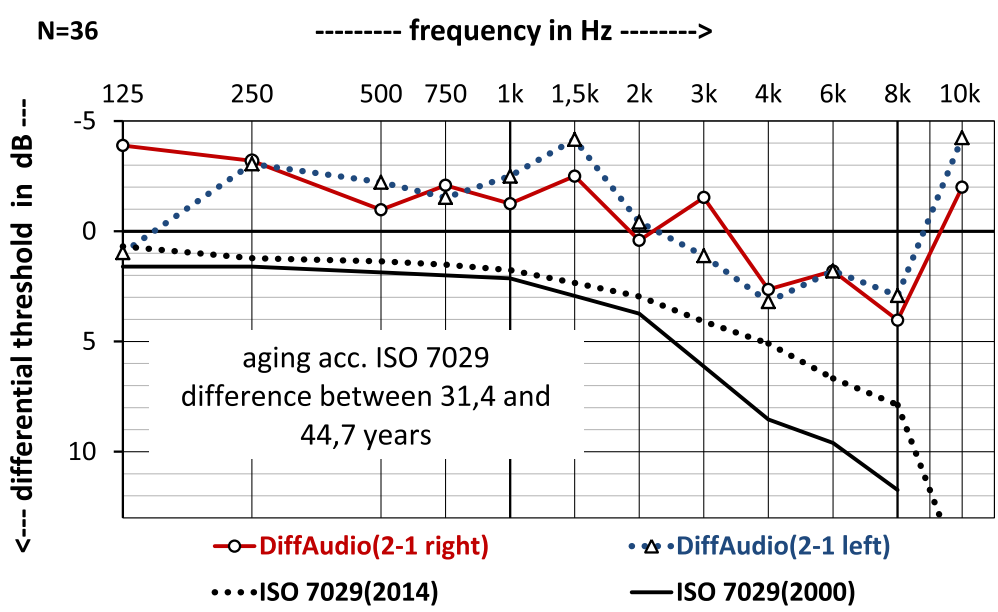

Fig. 3 Audiograms (difference between later audiogram (2) and first audiogram (1)) of military musicians taken within a 13.3 years time-span, thereby comparing both ears separately with the age-induced hearing loss according to the current ISO 7029:2000 [26] and the draft ISO 7029:2014 [27] at the same mean ages

according to the ISO standards with a deviation of about $-5 \mathrm{~dB}$, which corresponds to an entire setting level in the audiometer. At $10 \mathrm{kHz}$, there is a slight improvement in the hearing thresholds of $-2 \mathrm{~dB}$ at the right ear and $-4 \mathrm{~dB}$ at the left ear. While ISO 7029:2000 [26] has no standard values at $10 \mathrm{kHz}$, the provisional new ISO standard (2014) [27] for this frequency predicts a hearing loss of $15.6 \mathrm{~dB}$ between the ages of 33.4 and 44.7 years. The difference in hearing thresholds between the two ears varies between 0 and $5 \mathrm{~dB}$, with the curves crossing several times. Positive values indicate a deterioration in hearing.

The average differences between the hearing thresholds of the right and left ear are shown in Fig. 4. It can be seen that the asymmetry of the ears at frequencies below $1.5 \mathrm{kHz}$ is in a range between 0.2 and $-1 \mathrm{~dB}$. A clear exception is seen at $125 \mathrm{~Hz}$ (in the first audiometry), where the hearing of the right ear in comparison to the other is $4 \mathrm{~dB}$ worse than that of the left ear. By subtracting the average hearing thresholds, the agerelated, but also the noise-induced threshold differences are excluded, provided the effect is assumed to be the same for both ears. However, this does not seem to apply especially in the frequency range above $1 \mathrm{kHz}$. Between 2 and $7.5 \mathrm{~dB}$ we observe better hearing thresholds in the right ear. Averaged for 3, 4 and $6 \mathrm{kHz}$, the differences are about $5 \mathrm{~dB}$. That this is a real effect is shown in the statistical significance for the ear factor at $p=0.036$. A clear trend towards larger deviations at higher frequencies can be seen.

\section{Statistics}

The statistical verification of relationships was performed with a multifactorial analysis of variance (ANOVA) with repeated measurements based on 5 factors and their interactions. Three factors: the frequency with three

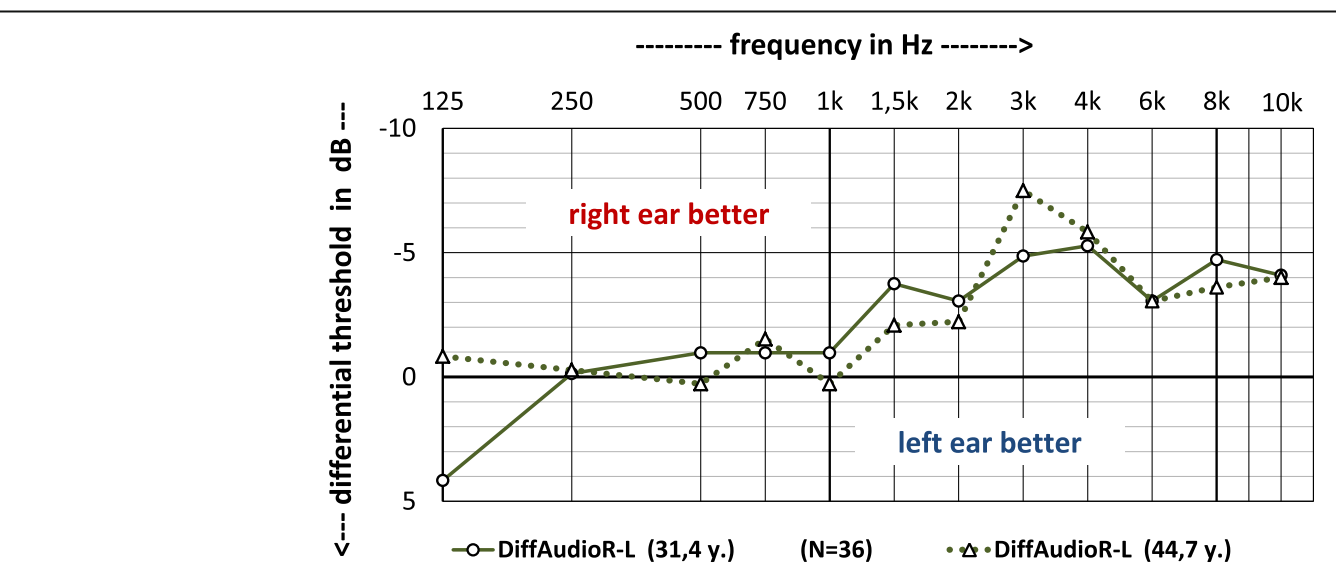

Fig. 4 Audiograms (difference between right and left ear) of military musicians taken within a 13.3 years time-span. Negative values show better hearing of the right ear and positive values of the left ear 
measurement levels $(3,4$ and $6 \mathrm{kHz}$, which are most sensitive to high sound levels!), The ear (right / left) and the audiogram (first and second) are the innersubjects factors (repeated measures) and two factors: the musician's instrument $(N=14)$ and the history of the experienced acoustic shocks, both mentioned in the questionnaire, represent between-subjects factors.

Significant differences were only found for the withinsubjects factors "frequency" and the "ear", while the auditory thresholds of audiograms 1 and 2 did not differ significantly for a time span of about 13 years. The between subject factor "instrument" with 7 trumpets, 6 clarinets, 5 trombones, 4 horns, 3 percussionists, 2 tubes and saxophones each and 1 baritone, conductor, electric bass, bassoon, transverse flute, keyboard and piano did not show any significant differences in the hearing thresholds ( $p=0.292$ as seen in Table 1). Also, the acoustic shocks mentioned in the questionnaire had no significant impact. All interactions of the individual factors were also not significant, as shown in Table 1, even those with the significant factors of frequency and ear. More interactions were calculated than indicated in Table 1, all of which were not significant.

\section{Noise induced hearing loss}

With the equation: $\mathrm{N} 50=[\mathrm{u}+\mathrm{v} * \lg (\mathrm{t} / \mathrm{t} 0)] *\left(\mathrm{~L}_{\mathrm{EX}, 8 \mathrm{~h}}-\mathrm{L}_{0}\right)^{2}$ from the ISO 1999 [8] the median of a hearing loss can be predicted. Here, $\mathrm{u}, \mathrm{v}$ and $\mathrm{L}_{0}$ are frequency-dependent table values of ISO 1999 [8]: $\mathbf{t}$ is the duration of the load, $\mathbf{t}_{\mathbf{0}} 1$ year and $\mathbf{L}_{\mathbf{E X}, \mathbf{s h}}$ the determined average sound load during the time period $\mathbf{t}$.

Table 1 Results of a multifactorial analysis of variance (ANOVA) with repeated measurements. Two between-subjects factors: instrument and acoustic shocks and three within-groups factors: audiogram (first and second), frequency (3, 4 and $6 \mathrm{kHz}$ ) and the ear (right/left) with four interactions

\begin{tabular}{l|rrr}
\hline between groups & $\boldsymbol{d} \boldsymbol{f}$ & $\boldsymbol{F}$ & $\boldsymbol{p}$ \\
\hline Instrument & 1 & 1.350 & 0.292 \\
Acoustic Shock & 1 & 0.748 & 0.402 \\
\hline within groups & & & \\
\hline Audiogram & 1 & 1.318 & 0.270 \\
Frequency & 2 & 20.518 & $<0.001$ \\
Ear & 1 & 5.353 & 0.036 \\
Audiogram * Frequency & 2 & 1.779 & 0.187 \\
Audiogram * Ear & 1 & 0.035 & 0.855 \\
Audiogram * Frequency * Ear & 2 & 1.505 & 0.240 \\
Frequency * Ear & 2 & 0.547 & 0.585 \\
\hline \multicolumn{2}{c}{ Significant factors and interactions (*) are expressed red bold } \\
\hline
\end{tabular}

The duration of sound exposure $t=13.3$ years. The average sound load $L_{\mathrm{EX}, 8 \mathrm{~h}}=91.4 \mathrm{~dB}(\mathrm{~A})$ as well as determined at microphone position A (See Fig. 1).

This results in predicted hearing losses for the frequencies $3 \mathrm{kHz}$ : $11.2 \mathrm{~dB}$, for $4 \mathrm{kHz}$ : $14.4 \mathrm{~dB}$ and for $6 \mathrm{kHz}$ : $9.6 \mathrm{~dB}$. These hearing losses are a rough estimate and are based on the assumption that the sonic load of $91.4 \mathrm{~dB}(\mathrm{~A})$ persisted for each musician and every working day during the 13.3 years without using ear protection devices or any other protective measures.

\section{Discussion}

When comparing the two studies with an average interval of 13.3 years in Fig. 2, first of all the great similarity of the average audiograms stands out. At all frequencies below $2 \mathrm{kHz}$ with the exception of $125 \mathrm{~Hz}$ in the left ear, the second audiometry is even better than the first examination. At $2 \mathrm{kHz}$, the hearing thresholds of both examinations are almost identical. The frequency at $3 \mathrm{kHz}$ shows a different behaviour for both ears. For the right ear, the second audiogram is $1 \mathrm{~dB}$ better and for the left ear the first one is. At 4, 6, and $8 \mathrm{kHz}$ frequencies, the auditory curves are parallel, with the auditory thresholds being better for the first audiogram than the second, as might be expected. Together with the $3 \mathrm{kHz}$ frequency, this range is the most sensitive to the harmful effects of noise. The hearing threshold at $10 \mathrm{kHz}$ behaves contrary to expectations. Although the presbyacusis is most pronounced at high frequencies, better thresholds are seen in the later study of military musicians. For clarification, these differences in the threshold values in Fig. 3 were highlighted and compared with the predicted age-impairment from ISO 7029 (2nd and 3rd editions) [26, 27]. The curves all have a similar course over the frequencies, but the ISO curves are clearly below the average threshold differences obtained from the measurements in the later and in the first audiogram (see legend to Fig. 2 called "DiffAudio"). These differences are greatest between the observed and the by ISO predicted thresholds at $10 \mathrm{kHz}$. Here, $-3 \mathrm{~dB}$ (both ears combined) contrasts with a value of $15.6 \mathrm{~dB}$ (ISO 7029:2014) [27]. The difference is therefore $18.6 \mathrm{~dB}$ and shows the opposite of a presbyacusis.

Musicians in classical orchestras (Chicago Symphony) [15] have high sound pressure levels with a mean of $90 \mathrm{~dB}(\mathrm{~A})$ created by their instruments while practicing their profession for $15 \mathrm{~h}$ per week. Converted to a $40 \mathrm{~h}$ shift per week the mean levels are $85.5 \mathrm{~dB}(\mathrm{~A})$. Impulse peaks reaches $143.5 \mathrm{~dB}$, above the upper exposure action value of $137 \mathrm{~dB}(\mathrm{C})$ [6].

Finnish members of the National Opera are exposed to sound levels above the upper action exposure values of $85 \mathrm{~dB}(\mathrm{~A})$ [28]. 
In an Australian study [29] mean $\mathrm{L}_{\mathrm{Ex}}$ levels for the brass section could be measured up to $90.7 \mathrm{~dB}(\mathrm{~A})$ and peak levels for the percussion section reached $146,9 \mathrm{~dB}(\mathrm{C})$.

In a Canadian study [1], the average sound levels of wind players were between $88 \mathrm{~dB}(\mathrm{~A})$ (oboe) and $94 \mathrm{~dB}(\mathrm{~A}$ ) (trumpet) during $3 \mathrm{~h}$. In comparison workers were exposed to industrial noise for about $2000 \mathrm{~h}$ per year, musicians for about $360 \mathrm{~h}$ per year. Thereby a correction value of $-7.4 \mathrm{~dB}$ was calculated and used.

In his measurements (Fig. 1) Pfander [22] uses the time constant "impulse" because of the high peak values, which occured especially in drums. Thus, the measured values are no longer directly comparable to the literature values. However, the burdens of military musicians may actually be higher than those of classical orchestra musicians, because of the over-proportionally large brasssection in comparison to the classical orchestra composition.

Nevertheless, the hearing thresholds at 3,4 and $6 \mathrm{kHz}$ with $p=0.270$ (audiogram) are not significantly different between the two examinations over 13.3 years of exposure. ISO 1999 [8] predicts noise-induced permanent threshold shift (NIPTS) for sound levels of $91.4 \mathrm{~dB}$ in 13.3 years of $11.2 \mathrm{~dB}(3 \mathrm{kHz}), 14.4 \mathrm{~dB}(4 \mathrm{kHz})$ and 9 . $6 \mathrm{~dB}(6 \mathrm{kHz})$. This will by far not be confirmed by the second investigation: Here we observed neither hearing loss (positive threshold values in Fig. 3) at $3 \mathrm{kHz}$ is $\pm 1 \mathrm{~dB}$, at $4 \mathrm{kHz} 3 \mathrm{~dB}$ and $2 \mathrm{~dB}$ at $6 \mathrm{kHz}$, NIPTS (ISO 1999) [8] nor presbyacusis (ISO 7029) [26, 27]. The difference between expected and observed value is about $10 \mathrm{~dB}$. In order to confirm the measured values by the ISO 1999 [8], average sound levels of about $83 \mathrm{~dB}$ would have to be assumed in the calculation.

In addition to the music played during working hours, additional exposure is added by playing music during leisure time and other noisy hobbies [20]. Further exposure is due to impulse noise in the regular military shooting practice. The dip in the audiogram between 2 and $8 \mathrm{kHz}$ also shows these effects of the impulse noise. In the questionnaire, 13 musicians stated that they had suffered an acoustic trauma during their time as soldiers. There is no indication from the audiogram of 8 musicians, so that the temporary hearing loss has receded. 5 musicians with the indication of an acoustic trauma had a corresponding sink in the audiogram. On the other hand, a further 12 musicians showed clear traces of past hearing damage due to impulse noise in the audiogram, without having reported this event in the questionnaire. In two cases, the question of acoustic trauma was not answered. In conclusion, less than one third $(N=5)$ of all observed/suspected acoustic traumata $(N=17)$ are identified by the survey. Therefore, the missing statistically significant correlation of the hearing thresholds with acoustic trauma (yes/no) $(p=0.402)$ can be explained. Sonic events that lead to clearly visible sinks in the audiogram are usually kept in mind by those affected, especially since their consequences can have an impact on the performance of the musicians. The discrepancy between the anamnestic questionnaire and the audiometric findings on acoustic trauma may well be the result.

The frequency-dependent differences at 3,4 and $6 \mathrm{kHz}$, which statistically describe the observed drop in the hearing curve are highly significant $(p<0.001)$. Since the thresholds at $8 \mathrm{kHz}$ are better than at $6 \mathrm{kHz}$, we can speak of a sink in the audiogram indicating a history of noise exposure.

In the current investigations, a significantly better hearing of the right than the left ear was found (see Table 1 and Fig. 3). That this is a real effect is shown in the statistical significance for the ear factor at $p=0.036$.

This difference may be due to a generally greater vulnerability of the left ear in comparison to the right ear [30] or to an asymmetric impact of damaging sound $[18,22]$. The latter would also be an indication of the origin of the hearing damage caused by impulse or shooting noise and especially not by the practice of music. Except for the flutes and horns most of the wind instruments radiate the sound symmetrically forward or upward.

he factor instrument also was not significant $(p=0.292)$, which is surprising in view of the large differences between the instruments in terms of maximum volume and their frequency spectrum. In the statistical review, the factor instrument had no significant influence nor possible interactions with the ear (not listed in Table 1). As early as 1985, Johnsson et al. [31] found that the instrument being played and the position in the orchestra did not lead to significant differences in hearing, which is confirmed by the current data.

Possible reasons for only small differences in the two investigations could be the different measurement techniques and the use of pulsed test tones in the second study with better measurement results, compared to continuous tones in the first study. However, there is no evidence in the literature, on the contrary, only marginal differences were found [32]. Similarly, the circumaural transducers of the second study have a better external noise attenuation than the supraaural transducers of the first study and measurement results are more reliable [33]. Another limitation may be the relatively small number of 36 participants, which, however, is of less importance in longitudinal than in cross-sectional studies. 


\section{Conclusions}

Overall, the musician's hearing has remained largely unchanged during the period under review, just over 13 years. The effect of noise on hearing remains far behind the predictions of ISO 1999 [8]. Similarly, the aging predicted by the ISO 7029 [26, 27] with progressive lowering of the thresholds in the collective of military musicians cannot be confirmed. In this sense we can speak of a delayed presbyacusis in musicians. This could be due to the highly selected collective of musicians with special training in hearing. By adaptation processes the practice of music with planned sound effect does not seem to be as damaging to the hearing due to the stapedius reflex, as unwanted pulsed industrial noise with the same sound levels. But this should not lead musicians to negligently deal with their hearing, but to ensure that special peak noise levels are avoided or mitigated with ear protection and to ensure adequate recovery of hearing during break-times.

\section{Acknowledgements}

Our thanks go to Gerald Fleischer for the idea of the study and the release of the datasets. Thanks also to Heinz Brinkmann, who provided us with the audiograms of the first investigation by Friedrich Pfander. Mr. Olaf Tech was kind enough to provide the report on the sound measurements of the Army Music Corps and the publication of Friedrich Pfander. Thanks also to Eckhard Hoffmann for his research and data collection for follow-up.

\section{Funding}

No funding.

Availability of data and materials

No additional data available.

\section{Authors' contributions}

Conception and design: RM and JS. Administrative support: RM. Provision of study materials and patients: RM. Collection and assembly of data: RM. Data analysis and interpretation: RM and JS. Manuscript writing: RM and JS. Final approval of manuscript: RM and JS.

\section{Ethics approval and consent to participate}

The data collection in this non-interventional study was part of the repeated health check-up's within the German occupational safety and health system (health check for military musicians enforced by law). As individuals participated voluntarily in the study and all data were analyzed anonymously, no ethical approval was required. This was basically stated by the Ethics Committee of the medical department (Justus-Liebig-Universität Gießen).

\section{Consent for publication}

The manuscript contains no individual person's data in any form.

\section{Competing interests}

The authors declare that they have no competing interests.

\section{Publisher's Note}

Springer Nature remains neutral with regard to jurisdictional claims in published maps and institutional affiliations.

\section{Author details}

1Justus-Liebig-Universität Giessen, Aulweg 123, 35392 Giessen, Germany. ${ }^{2}$ Institut und Poliklinik für Arbeits- und Sozialmedizin am Universitätsklinikum Giessen und Marburg, Aulweg 129, Giessen 35392, Germany.
Received: 26 January 2018 Accepted: 29 March 2018

Published online: 12 April 2018

\section{References}

1. Qian CL, Behar A, Wong W. Noise exposure of musicians of a ballet orchestra. Noise Health. 2011;13(50):59-63.

2. Smith C, Beamer S, Hall S, Helfer T, Kluchinsky TA Jr. A preliminary analysis of noise exposure and medical outcomes for department of defense military musicians. US Army Med Dep J. 2015;3(Jul.-Sept.):76-82.

3. Gonçalves CG, Lacerda AB, Zeigelboim BS, Marques JM, Luders D. Auditory thresholds among military musicians: conventional and high frequency. Codas. 2013;25(2):181-7.

4. Patil ML, Sadhra S, Taylor C, Folkes SE. Hearing loss in British Army musicians. Occup Med. 2013;63(4):281-3.

5. Axelsson A, Lindgren F. Hearing in classical musicians. Acta Otolaryngol. 1981;91(Suppl 377):3-74

6. EU Directive 2003/10/EC of the European Parliament and of the council, 2007.

7. McBride D, Gill F, Proops D, Harrington M, Gardiner K, Attwell C. Noise and the classical musician. BMJ. 1992;305:1561-3.

8. ISO 1999. Acoustics - estimation of noise induced hearing loss. Geneva: International Organization for Standardisation; 2013.

9. Brusis T. Akuter Hörverlust beim Orchestermusiker. HNO. 2010;59:664-73.

10. Karlsson $K$, Lundquist $P G$, Olaussen $T$. The hearing of symphony orchestra musicians. Scand Audiol. 1983:12:257-64.

11. Kähäri KR, Axelsson A, Hellström PA, Zachau G. Hearing assessment of classical orchestral misicians. Scand Audiol. 2001;30:13-23.

12. Kähäri KR, Axelsson A, Hellström PA, Zachau G. Hearing development in classical orchestral musicians. A follow-up study. Scand Audiol. 2001;30:141-9.

13. Obeling L, Poulsen T. Hearing ability in Danish symphony orchestra musicians. Noise Health. 1999;2:43-9.

14. Royster JD, Royster LH, Killion MC. Sound exposures and hearing thresholds of symphony orchestra musicians. J Acoust Soc Am. 1991;89(6):2793-803.

15. Toppila EM, Koskinen H, Pyykkö I. Hearing loss among classical-orchestra musicians. Noise Health. 2011;13:45-50.

16. Ostri B, Eller N, Dahlin E, Skylv G. Hearing impairment in orchestral musicians. Scand Audiol. 1989;18:243-9.

17. Reuter K, Hammershøi D. Distortion product otoacoustic emission of symphony orchestra musicians before and after rehearsal. J Acoust Soc Am. 2007;121(1):327-36.

18. Schmidt JH, Pedersen ER, Møller Juhl P, Christensen-Dalgsaard J, et al. Sound exposure of symphony orchestra musicians. Ann Occup Hyg. 2011; 55:893-905.

19. Sataloff RT. Hearing loss in musicians. Am J Otol. 1991;12:122-7.

20. Emmerich $\mathrm{E}$, Rudel L, Richter F. Is the audiologic status of professional musicians a reflection of the noise exposure in classical orchestral music? Eur Arch Otorhinolaryngol. 2008;265(7):753-8.

21. Bo $M$, Clerico $M$, Pognant F. Parametric method for the noise risk assessment of professional orchestral musicians. Noise Health. 2016:18(85):319-28.

22. Pfander F. Akustische Belastung der Bundeswehrmusiker und ihre arbeitsmedizinische Beurteilung. Wehrmedizinische Monatsschrift. 1985; 29(8):329-31.

23. ISO 389-8. Acoustics - reference zero for the calibration of audiometric equipment - part 8: reference equivalent threshold sound pressure levels for pure tones and circum-aural earphones. Geneva: International Organization for Standardization; 2004.

24. ISO 389-5. Acoustics - reference zero for the calibration of audiometric equipment - part 5: reference equivalent threshold sound pressure levels for pure tones in the frequency range $8 \mathrm{kHz}$ to $16 \mathrm{kHz}$. Geneva: International Organization for Standardization; 1999.

25. ISO 389-1. Acoustics - reference zero for the calibration of audiometric equipment - part 8: reference equivalent threshold sound pressure levels for pure tones and supra-aural earphones. Geneva: International Organization for Standardization; 2000.

26. ISO 7029. Acoustics - statistical distribution of hearing thresholds as a function of age. Geneva: International Organization for Standardisation; 2000.

27. ISO 7029 (draft). Acoustics - statistical distribution of hearing thresholds as a function of age. Geneva: International Organization for Standardisation; 2014

28. Laitinen HM, Toppila EM, Olkinuora PS, Kuisma K. Sound exposure among the Finnish National Opera personnel. Appl Occup Environ Hyg 2003;18(3):177-82 
29. O'Brien I, Wilson W, Bradley A. Nature of orchestral noise. J Acoust Soc Am 2008;124(2):926-39.

30. Pirilä T, Jounio-Ervasti K, Sorri M. Left-right asymmetries in hearing threshold levels in three age groups of a random population. Audiology. 1992;31:150-61.

31. Johnson DW, Sherman RE, Aldridge J, Lorraine A. Effects of instrument type and orchestral position on hearing sensitivity for 0.25 to $20 \mathrm{kHz}$ in the orchestral musician. Scand Audiol. 1985;14:215-21.

32. Burk MH, Wiley TL. Continuous versus pulsed tones in audiometry. Am J Audiol. 2004;13(1):54-61.

33. Flamme GA, Geda K, Mcgregor KD, Wyllys K, Deiters KK, et al. Stimulus and transducer effects on threshold. Int J Audiol. 2015;54(Supl. 1):19-29.

Submit your next manuscript to BioMed Central and we will help you at every step:

- We accept pre-submission inquiries

- Our selector tool helps you to find the most relevant journal

- We provide round the clock customer support

- Convenient online submission

- Thorough peer review

- Inclusion in PubMed and all major indexing services

- Maximum visibility for your research

Submit your manuscript at www.biomedcentral.com/submit 